ORIGINAL ARTICLE

\title{
Localized Prostate Cancer, Retropubic Radical Prostatectomy: Surgical Complications, Single Centre Study.
}

\author{
MUHAMMAD ALI SOHAIL ${ }^{1}$, GULSHAN ALI MEMON², SHAHIDA BALOCH ${ }^{3}$, MUMTAZ ALI CHANDIO ${ }^{4}$, ZAMEER HUSSAIN \\ LAGHARI ${ }^{5}$ \\ ${ }^{1}$ Professor, Urology, PUMHSW, SBA. \\ ${ }^{2}$ Professor Surgery, Surgery, PUMHSW, SBA. \\ ${ }^{3}$ Senior Registrar, Surgery, PUMHSW, SBA. \\ ${ }^{4}$ Assistant Professor, Urology, PUMHSW, SBA \\ ${ }^{5}$ Associate Professor, Surgery, LUMHS Jamshoro. \\ Correspondence to: Muhammad Ali Sohail, Professor of urology, Email: talkturoman@yahoo.com
}

\begin{abstract}
Background: For organ-confined disease in carcinoma of prostate the primary curative procedure that is well identified is the retro pubic radical prostatectomy.

Objective: To assess the complications related to surgery of prostate after open retro pubic radical prostatectomy.

Materials and Methods: Retropubic radical prostatectomy was performed in 75 subjects suffering from localized cancer of prostate in last 05 years, at the urology department. Open retropubic radical prostatectomy procedure represented by Walsh as a classic method was adapted. Disease progression and caliber of life indices like potency and urinary continence were noted during the follow up.

Result: There were total 75 patients in current study. Mean age of patients was 63.3 years. Out of 75 patients, 70 were married and 05 patients were unmarried, 25 were from urban areas, while 50 were from rural area, 35 were educated and 45 were uneducated, 05 patients had positive family history for prostatic malignancy, while 70 patients had no family history of prostatic carcinoma. Out of 75 patients, 63, 65 and 69 patients were continent, at 10, 06 and 12 months; however, 05, 04 and 04 had stress incontinence at 10, 06 and 12 months; and 07, 03 and 01 had mixed incontinence urge and stress at 06 and 12 months; 05, 03 and 01 had total incontinence at 06 and 12 months. Subjects with incontinence are trained exercises concerned with pelvic floor.

Conclusion: The retro-pubic thorough prostatectomy is the typical management of early cancer of prostate and a number of complications are associated with this technique of surgery. It had a vertical knowledge curl. Large figure of patients and improvement in techniques are needed to attain the perfect outcomes.

Keywords: Carcinoma, prostate, radical, prostatectomy.
\end{abstract}

\section{INTRODUCTION}

Cancers are ranked as a principal reason for mortality throughout the globe. Malignancies are chief barriers to accumulative life expectation. 1 In accordance to estimations of WHO during 2019,, 2 cancers rank as first or second important reason of mortality in populations of 112 of 183 nations, before the 70 years of age, and rank as third or fourth in additional 23 nations. In a large number of countries, the death rates had a decline in subjects suffering from stroke and coronary cardiac ailments in relation to cancers [1]. There are numerous management options for malignancy confined to the prostate like retropubic radical prostatectomy or radiation therapy. The most often implemented procedure in confined cancer of prostate is the retro-pubic radical prostatectomy, which is well-known primary curative procedure $[\underline{3}, \mathbf{4}]$. Although it is well-known common procedure, but is also associated with many complications. The frequency of complications is decreased in the other procedures of management in confined carcinoma of prostate. Different complications of this surgical method have been highlighted in current study.

The frequency, survival rate, pervasiveness and death of the subjects were analysed. Different resources throughout the globe were adopted to observe the occurrence with uniform age and rate of mortality amongst men. The EUROPREVAL study was used to estimate the prevalence and for survival European and other resources were adopted. Outcomes of different published data were concise. The frequency of prostatic carcinoma differs broadly round the globe, USA and Canada had the maximum rates. Since 1960s the frequency of the prostatic carcinoma had increased gradually in many nations. A large increase was noted in USA in the late 1980s and early 1990s. The incidence is also increasing in nations with previous decreased levels such as in India. The survival of subjects suffering from cancer of prostate had improved thru the 1970s and 1980s; this improvement in survival rate was further observed in 1990s due to early diagnosis and treatment. A wide difference in the survival rates in Europe and UK were noted. The survival rates were high in USA in comparison to Europe. Also, in Europe a wide-ranging difference in the prevalence of cancer of prostate was observed; with increased frequency and increased lifeexpectancy were noted. The cancers of prostate share about $15.0 \%$ of all cancers prevalent in male. In many nations the mortality related with cancer of prostate had increased, less than magnitude of occurrence, which is due to increase in survival rates. In the USA, Canada, England, France and Austria and many other nations the death rates due to prostate cancer were decreased during the era from mid to late 1990s. The increase in frequency of prostatic carcinoma had been related to analytical errors. It might have effect on mortality outcomes with incorrect entry of artifact as prostatic carcinoma is a cause of death. With the availability of PSA (prostate specific antigen), the new registration of the prostate cancer had been raised since 
1990s. Recently there is slight decrease in deaths due to cancer of prostate, which may contribute to early detection of disease and/or due to outcomes of attributing bias. Modifications in ailment treatment are undoubtedly more significant. There are numerous argues against the populace established analysis for prostatic carcinoma [5].

The objective of this study was to assess the different complications related to prostatic surgery. This study will help in identification and management of complications of prostatic surgery than by paying attention may reduce the morbidity and mortality.

\section{METHODLOGY}

$\mathrm{PMCH}$ is a tertiary care referral hospital. About 320 subjects suffering from prostatic carcinoma during March 2015 to February 2020 were managed at this institutional hospital. 160/320 subjects had locally advanced cancer of prostate and 100/320 had metastatic disease at the admission. 110/320 subjects had confined cancer of prostate. Open retro-pubic radical prostatectomy was performed in 75/110 subjects. Consent was obtained from all the patients. A single surgeon performed surgeries on all the cases. Data was collected after ethical permission; sociodemographic variables were recorded on predesigned Performa.

History and physical examinations were performed in all the subjects. Serum prostate specific antigen (SPSA) was advised in subjects presenting with lower urinary tract symptoms, with age more than 50 years and having life expectancy of more than 10 years. If the serum PSA was more than $4 \mathrm{ng} / \mathrm{ml}$ or digital rectal examination was abnormal, patients were advised for prostate biopsy. The metastatic lesions were excluded by radiology including $x$ ray chest and ultrasound abdomen and other haemetological investigations. Chest X-ray and ultrasound of whole abdomen was done. Loco-regional spread and existence of pelvic lymphadenopathy were excluded by CT scan pelvis. When serum levels of PSA were more than 10 $\mathrm{ng} / \mathrm{ml}$ or Gleason grade were more than 7 , the patients were advised for bone scan. Data was analyzed by SPSS version 23. Mean was calculated for quantitative variables. Different complications were recorded on proforma by keeping proper record of patients.

Surgical Method: Standard method of radical retro-pubic prostatectomy as designed by Walsh was carried out on all the subjects. [6] The specimens were collected. The reconstruction of bladder neck and urethral anastomosis with 4/0 poly-glactin finished over a silicon Foley's catheter $(16 \mathrm{~F})$. A suctioning channel was retained in the retro-pubic area.

Follow-up: Subjects were arranged to step, and orally liquids were allowed in the following morning subsequently to the technique, and semi-solids were also given. All patients were followed up 01-06 and 12 monthly for the first year. At each appointment, subjects were asked for any symptoms if they have developed, per rectal examination was performed, directed for uroflowmetry and serum PSA.

\section{RESULTS}

There were total 75 patients in current study. Mean age of patients were 63.3 years, minimum 50 and maximum 75 years. As shown in table 1. Table 2 shows the distribution of different age groups, frequency and percentage wise. Patient's demographic outlines have been presented in Table 3. Preoperative needle biopsy of the prostate was carried out in subjects to confirm the presence of carcinoma prostate.

\begin{tabular}{|c|c|c|}
\hline Mean & \multicolumn{2}{|c|}{63.3066} \\
\hline Median: & \multicolumn{2}{|c|}{64} \\
\hline Mode: & \multicolumn{2}{|c|}{65} \\
\hline Range; & \multicolumn{2}{|c|}{25} \\
\hline Minimum: & \multicolumn{2}{|c|}{50} \\
\hline Maximum: & \multicolumn{2}{|c|}{75} \\
\hline \multicolumn{3}{|c|}{ Table 2: Age group } \\
\hline Age group & Frequency & Percentage \\
\hline $50-55$ years & 05 & 6.666 \\
\hline $56-60$ years & 10 & 13.333 \\
\hline $61-65$ years & 45 & 60.00 \\
\hline $66-70$ years & 10 & 13.333 \\
\hline $71-75$ years & 05 & 6.666 \\
\hline
\end{tabular}

\begin{tabular}{|l|l|l|}
\hline Table 3: Demographic values & \\
\hline Marital status & & \\
\hline married & 70 & 93.333 \\
\hline Un married & 05 & 6.666 \\
\hline Residence & & \\
\hline Urban & 25 & 33.333 \\
\hline rural & 50 & 66.666 \\
\hline education & & \\
\hline uneducated & 35 & 46.666 \\
\hline educated & 45 & 60.00 \\
\hline Family history & & \\
\hline positive & 05 & 6.666 \\
\hline negative & 70 & 93.333 \\
\hline
\end{tabular}

\begin{tabular}{|l|l|l|}
\hline \multicolumn{3}{|l|}{ Table 4: IPSS, PSA, Gleason Score } \\
\hline IPSS Score & & \\
\hline Mild & 15 & 20.00 \\
\hline Moderate & 45 & 60.00 \\
\hline Severe & 15 & 20.00 \\
\hline Preoperative S.PSA (ng/ml) & & \\
\hline$<4 \mathrm{ng} / \mathrm{ml}$ & 0 & 0.00 \\
\hline $4-10 \mathrm{ng} / \mathrm{ml}$ & 52 & 69.333 \\
\hline $10-20 \mathrm{ng} / \mathrm{ml}$ & 19 & 25.333 \\
\hline$>20 \mathrm{ng} / \mathrm{ml}$ & 04 & 5.333 \\
\hline Gleason's Score & & \\
\hline 4 & 21 & 28.00 \\
\hline 6 & 24 & 32.00 \\
\hline 8 & 18 & 24.00 \\
\hline 9 & 12 & 16.00 \\
\hline
\end{tabular}

Out of 75 patients 70 were married, and 05 unmarried, 25 were from urban areas, while 50 were from rural, 35 were educated and 45 were uneducated and 05 had positive family history of prostatic malignancy, while 70 patients had no family history of prostatic carcinoma. as shown in table 3. Sequence of IPSS scores, levels of PSA preoperatively and Gleason Score have been shown in table 4. Out of 75 patients 63,65 and 69 were continent at 10, 06 and 12 months; subjects with incontinence were trained pelvic floor exercises. 05, 04 and 04 had stress incontinence at 10, 06 and 12 months; and 07, 03 and 01 
had mixed incontinence urge and stress at 06 and 12 months. 05, 03 and 01 had total incontinence at 06 and 12 months, as shown in figure 1. At 12th month, 16/75 subjects developed contractures of bladder neck. 60 patients were impotent at 12 months. In 65 / 75 subjects the cancer control was present. 10 subjects presented with renal failure at 12 months. 10 subjects developed mild stricture at the anastomotic site, out of these, 5 subjects reacted well by only single dilatation and 03 subjects needed bladder neck incisions.

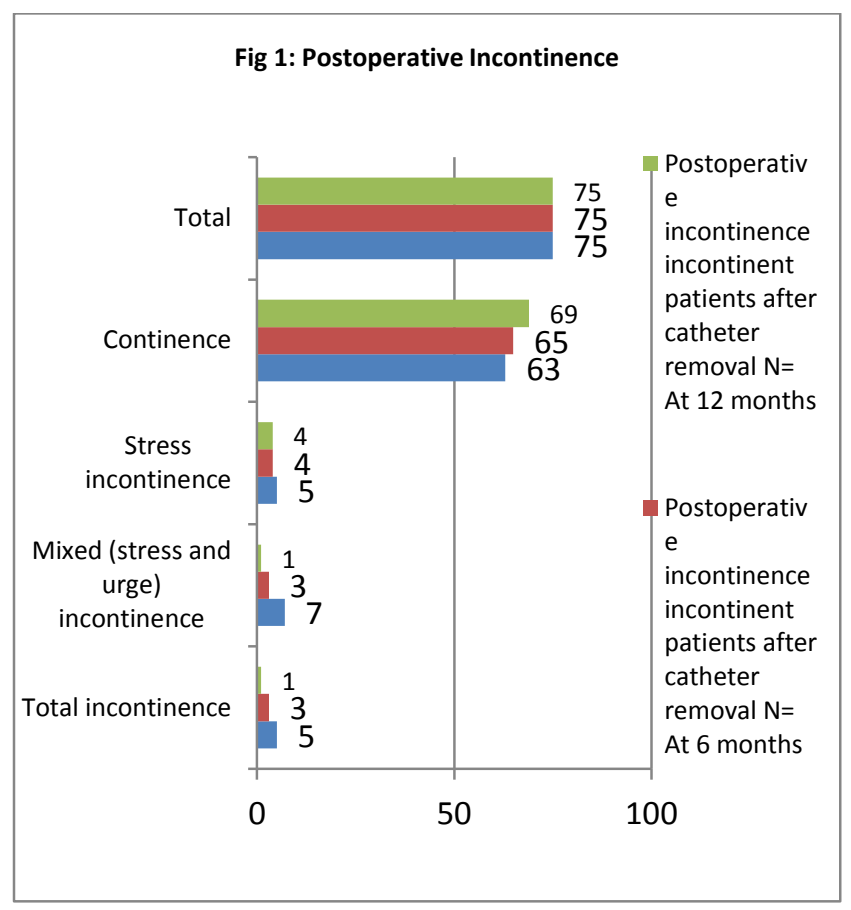

\section{DISCUSSION}

The cancer of prostate is ranked as the $4^{\text {th }}$ leading malignancy in male gender throughout the globe. The maximum frequency of Carcinoma of prostate is found in North Americans and Scandinavians, particularly in AfricanAmericans $(272 / 100,000)$. The frequency in the Asian inhabitants is the lower most $(1.9 / 100,000)$ [7]. There were no unique customary management techniques for confined cancer of the prostate. Watchful waiting, radiation therapy or surgical techniques are different choices for patients. At the present times typical treatment recognized for confined cancer of prostate is radical retropubic prostatectomy (RRP). Open surgery for confined cancer of prostate had been confronted by the arrival of laparoscopy and other convenient procedures. In spite of the advancement; the open technique still remains a "gold standard" for control of carcinoma and better quality of life [6]. It is technically the most challenging procedure in the urology and is associated with substantial complications. The control of carcinoma, preservation of urinary continence and sexual functions are the main goals accomplished during this surgery. Intra-operative or post-operative bleeding, thrombo-embolic phenomenon and loss of any goals are the important complications of this surgery. But with well knowledge of regional anatomy, decent surgical abilities and constant practices in the choice of subjects, the surgery related complications had decreased to a tolerable levels.

The frequency of cancer of prostate is decreased in India in comparison to the west. In India the statistics regarding carcinoma of prostate are not sufficient, because radical retropubic prostatectomy is practiced in a limited number of centers. This might be due to the inadequate skill with surgical process. Here we presented surgical procedure skills, surgical adverse outcomes and consequences. Although we have limited skills, but a message through this to the urologists is to adopt this procedure as the first line management in confined carcinoma of prostate. In the beginning, we controlled the progression of cancer and urinary continence but were unable to reserve the potency in most of subjects. Bladder neck as well as seminal vesicle sparing could not be carried to preserve the impotency, as there were no suitable candidates. In literature review from country, we did not find such techniques performed by surgeons.

The frequency of post-operative haemorrge reviewed in literature was $0.50 \%$, in our study we observed as $01.9 \%$ [8]. Patients were managed conventionally. In current study bladder neck contractures and urinary incontinence were not increased. Subjects were continent at one month and there was no contracture of bladder neck.

Frequency of bladder neck in previous studies was observed as $0.5-10 \%$, in current study the frequency of contractures in bladder neck was analyzed as $15.40 \%$ $(8 / 52)$. Bladder neck dilatation was performed in two subjects three times without achievement, then bladder neck incision with Collin's knife was carried out and subjects are doing well. Single time bladder neck dilatation was required in remaining 06 subjects with mild contractures.

Intrinsic sphincter insufficiency is mostly responsible for urinary incontinence. Incontinence frequency was reported as $08.4 \%$ by Stanford et al [9]. With the institution of intussusception of bladder neck $98.0 \%$ of the cases were pad-free at 12 months [10]. In current study 49/52(94.3\%) were continent at one year. Two (03.8\%) were with stress continence occasionally and one $(01.9 \%)$ subject was with total incontinence at one year. Pelvic floor exercises with imipramine were advised them to improve continence.

Three essential factors responsible for preservation of erectile function are potency before operation, age of subjects under 65 years and ability of preserving neuromuscular bundle. An authenticated inquiry form was used to access the sexual function and was observed that $86.0 \%$ of the subjects were capable to attain erection with sildenafil citrate or without it, at 18 months [11]. In another study conducted by Parsons et al., recovery from erectile dysfunction at three months was $42.0 \%$, at six months $49.0 \%$ and at one year $73.0 \%$ [12]. Bilateral neuro-vascular bundle was well-maintained in both above studies. Potency incidence was $65.0 \%$, from them in only one subject neurovascular bundle was well-preserved. Regardless of preoperative potency prominence 45 of our subjects become impotent after radical retropubic prostatectomy, due to the reasons that we could not be able to preserve the neuromuscular bundle. With improved RRP it was possible to preserve the neuromuscular bundle and thus preserved the 
potency. In the 07 subjects the potency was maintained by the support of Sildenafil orally.

\section{CONCLUSION}

In early confined cancer of prostate, open RRP (radical retropubic prostatectomy) is curative. The selection of the suitable subjects is the apprehension. The concern is to control the cancer, to improve quality of life and preserve potency after the RRP. The prompt approach for localized illness in initial cancer of prostate gives tremendous chances for cure with good life quality.

Ethics Approval: The ethical review committee approved after ethical review.

Consent To Participate: Inscribed and spoken agreement was got from patients and next of kin.

Funding: No any organization economically supported for this. The writers had bearded all the expenses.

Acknowledgements: We thank to all the contributors and staff and peoples who provided the valuable facts.

Authors' Contributions: All persons who meet authorship criteria are listed as authors, and all authors certify that they have participated in the work to take public responsibility of this manuscript. All authors read and approved the final manuscript.

Conflict of Interest: No conflict of interest affirmed.

\section{REFERENCES}

1. Bray F, Laversanne M, Weiderpass E, Soerjomataram I. The ever-increasing importance of cancer as a leading cause of premature death worldwide. Cancer. In press.

2. World Health Organization (WHO). Global Health Estimates 2020: Deaths by Cause, Age, Sex, by Country and by Region, 2000-2019. WHO; 2020. Accessed December 11, 2020. who.int/data/gho/data/themes/mortality-and-globalhealth-estimates/ghe-leading-causes-of-death

3. Marcos F, Oliveira LC, Joao F, Neto N, Leite KR, Srougi M. Prediction of pathological stage in prostate cancer through the percentage of involved fragments upon biopsy. BJU Int. 2005;31:445-51. [PubMed] [Google Scholar]

4. Goyal NK, Kumar A, Acharya RL, Trivedi S, Dwivedi US, Singh PB, et al. Prediction of biochemical failure in localized carcinoma of prostate after radical prostatectomy by Neurofuzzy. Indian J Urol. 2007;23:14-7. [PMC free article] [PubMed] [Google Scholar]

5. Quinn M, Babb P. Pattern and trends in prostate cancer incidence, survival, prevalence and mortality. Part I: International comparisons. $\mathrm{Br} \quad J \quad$ Urol. 2002;90:16173. [Google Scholar]

6. Walsh PC, Partin AW. Campbell-Walsh Urology. 9th ed. Philadelphia: Saunders; 2007. Anatomical radical retropubic prostatectomy; p. 2956. [Google Scholar]

7. Quinn M, Babb P. Pattern and trends in prostate cancer incidence, survival, prevalence and mortality. Part I: International comparisons. $\mathrm{Br} \quad J \quad$ Urol. 2002;90:16173. [Google Scholar]

8. Hadican SP, Walsh PC. Post-operative bleeding following radical retropubic prostatectomy. J Urol.1994;152:11813. [PubMed] [Google Scholar]

9. Stanford JL, Feng Z, Hamilton AS, Gilliland FD, Stephenson RA, Eley JW, et al. Urinary and sexual function after radical prostatectomy for clinically localized prostate cancer: The Prostate Cancer Outcomes Study. JAMA. 2000;283:35460. [PubMed] [Google Scholar]

10. Walsh PC, Marschke PL. Intussusception of the reconstructed bladder neck leads to earlier continence after radical prostatectomy. Urology. 2002;59:9348. [PubMed] [Google Scholar]

11. Walsh PC, Marschke P, Ricker D, Burnett AL. Patientreported urinary continence and sexual function after anatomic radical prostatectomy. Urology. 2000;55:5861. [PubMed] [Google Scholar]

12. Parsons JK, Marschke P, Maples P, Walsh PC. Effect of methylprednisolone on return of sexual function after nerve sparing radical retropubic prostatectomy. Urology. 2004;64:987-90. [PubMed] [Google Scholar] 